\title{
Morfologia improdutiva como porta de entrada para a morfologia relacional
}

\author{
Irene FALLY (D \\ Universidade de Viena (UNIVIE)
}

RESUMO

Neste trabalho, se apresenta uma resenha da conferência de Jenny Audring, professora assistente da Universidade de Leiden, sobre a morfologia improdutiva. Na sua palestra, a investigadora aborda padrões morfológicos na formação de palavras que não são produtivos na linguagem corrente, e mostra quais são os desafios que estes suscitam à abordagem teórica da morfologia. A investigadora propõe o enquadramento teórico da Morfologia Relacional (JACKENDOFF; AUDRING, 2019), abordagem relacionado com a Morfologia Construcional e a Arquitetura Paralela. Recorrendo a exemplos de padrões morfológicos improdutivos, Audring mostra como esta teoria pode ser aplicada e usada na análise de palavras complexas, e

OPEN ACCESS

EDITADO POR Raquel Freitag

AVALIADO POR Emanuel Quadros

DATAS

Recebido: 21/07/2020

Aceito: $18 / 08 / 2020$ Publicado: 01/09/2020

COMO CITAR

Fally, I. (2020)

Morfologia improdutiva como porta de entrada para a morfologia relacional. Revista da Abralin, v. 19, n. 2, p. 1-3, 2020. como pode lidar com os desafios da morfologia improdutiva.

\section{ABSTRACT}

This article reviews the lecture of Jenny Audring, assistant professor at the University of Leiden, on the topic of unproductive morphology. Her lecture focuses on morphological patterns in word formation that are no longer productive in current language usage and on the problems these patterns pose to morphological theory. In answer to these problems Audring presents the framework of Relational Morphology (JACKENDOFF; AUDRING, 2019), a sister theory of Construction Morphology that is based within the Parallel Architecture framework. Using examples of unproductive morphological patterns, Audring illustrates how this framework can be applied and used in the analysis of complex words, and how it can deal with the challenges posed by unproductive morphology. 


\section{REVISTA DA ABRALIN}

PALAVRAS-CHAVE

Formação de palavras. Morfologia. Teoria Linguística.

\section{KEYWORDS}

Word formation. Morphology. Linguistic Theory.

A formação de palavras é uma área da morfologia muito estudada, tanto a nível descritivo, como a nível teórico. No entanto, uma grande parte dos estudos foca-se no modo como novas palavras podem ser geradas, isto é, em mecanismos de formação de palavras produtivos, deixando de lado padrões considerados improdutivos. Na sua conferência Abralin ao Vivo, Jenny Audring, professora assistente na Universidade de Leiden, aborda a problemática da morfologia improdutiva, identifica os desafios que esta suscita à abordagem teórica da morfologia e propõe um novo enquadramento teórico, a Morfologia Relacional (JACKENDOFF; AUDRING, 2019), para analisar e explicar padrões improdutivos.

Audring parte da ideia de que uma teoria morfológica deveria explicar todas as palavras, mesmo aquelas que do ponto de vista sincrônico já não podem ser produzidas espontaneamente, ou seja, as palavras que nas teorias morfológicas são caracterizadas como lexicalizadas. Ademais, ilustra os problemas que estas palavras levantam para a análise, detalhando quatro tipos de improdutividade morfológica na formação de palavras no senso largo. O primeiro tipo consiste em casos onde partes das palavras não existem em isolamento, como é o caso de cran- na palavra cranberry ('oxicoco'). Noutro tipo, palavras ou partes de palavras têm um significado imprevisível, como por exemplo a palavra inglês honey no composto honeymoon ('lua de mel'). Além disto, existem também padrões flexionais e derivativos com alomorfia onde aparecem formas imprevisíveis, embora tenham um significado relacionado como na formação do comparativo do inglês good ('bom') que resulta better ('melhor'). O último tipo discutido pela conferencista são os padrões improdutivos strictu sensu, quer dizer, certos procedimentos já não disponíveis para a formação de novas palavras, como a formação de adjetivos em inglês a partir do sufixo -en em wooden ('de madeira').

Os quatro tipos de improdutividade colocam problemas à abordagem teórica da morfologia, problemas esses que estão relacionados, por um lado, com a ordem e a classificação das palavras e, por outro, com a delimitação entre as várias componentes da linguagem. Segundo Audring, uma teoria morfológica tem que afrontar todas as questões suscitadas tais como, a identificação duma palavra como membro de um padrão morfológico, a faculdade dos falantes de reconhecer relações formais ignorando o significado, de estabelecer relações entre alomorfos não idênticos na forma compartilhando o significado, e de identificar o que diferencia padrões produtivos de padrões improdutivos.

Na visão de Audring, é necessária a introdução de uma teoria que permite a existência de listagem de palavras complexas com as estruturas internas, e onde o léxico é intensamente integrado com a gramática, como é o caso da Morfologia Relacional (JACKENDOFF; AUDRING, 2019), um 


\section{REVISTA DA ABRALIN}

enquadramento teórico baseado na Arquitetura Paralela de Jackendoff (2002) e relacionado com a Morfologia Construcional (BOOIJ, 2010).

Na perspectiva da Morfologia Relacional, o saber linguístico dos falantes é organizado em vários níveis de estrutura, quer dizer, por cada palavra são listados o significado, a estrutura morfossintática, a fonologia e a ortografia. Claramente, os níveis não são isolados, existem ligações de interface entre eles. Além destas associações entre as várias interfaces, estabelecem-se também ligações relacionais ao nível da estrutura. O reconhecimento da mesma estrutura em várias palavras permite uma generalização ao nível estrutural e a formação de esquemas. Nesta abordagem teórica, o esquema, também central na Morfologia Construcional, tem um valor mais descritivo e substitui as regras com o seu caráter processual. Como aponta Audring, a utilização de esquemas para a generalização evita o problema de formular regras improdutivas, mas permite também analisar padrões produtivos.

Além disso, Audring explica que o papel dos esquemas é o de mostrar que a estrutura duma palavra não é arbitrária, e que existe pelo menos uma motivação parcial, sem necessariamente estabelecer uma hierarquia entre as palavras relacionadas pelos esquemas.

A conferencista conclui com a observação de que neste enquadramento teórico, em contraste com teorias gerativas, são as palavras e estruturas inventariadas no léxico a formarem a base do saber linguístico, a produtividade é relegada ao segundo plano: a geração de novas palavras complementa o léxico, mas não é em si o aspecto central que determina o saber linguístico.

Tal como demonstrado pelas questões colocadas pelos espectadores, existem ainda vários aspetos da morfologia que têm de ser abordados pela pesquisa, por exemplo a ocorrência de lacunas morfológicas, ou os fatores governando a (im)produtividade na formação de palavras. A conferência de Audring propõe um contraste interessante em relação às análises morfológicas gerativas, e fornece uma nova perspectiva sobre a produtividade, tema forte na área de morfologia, e a análise de padrões de formação de palavras improdutivos.

\section{REFERÊNCIAS}

UNPRODUCTIVE Morphology. Conferência apresentada por Jenny Audring. [s.l., s.n], 2020.1 vídeo (1h 25min 25s). Publicado pelo canal da Associação Brasileira de Linguística. Disponível em: <https://youtu.be/TdWGKALmmhM>. Acesso em: 16 jul. 2020.

BOOIJ, G. Construction morphology. Oxford, New York: Oxford University Press, 2010.

JACKENDOFF, R. Foundations of Language. Oxford: Oxford University Press, 2002.

JACKENDOFF, R.; AUDRING, J. The Texture of the Lexicon: Relational Morphology and the Parallel Architecture. Oxford: Oxford University Press, 2019, DOI:10.1093/oso/9780198827900.001.0001. 